\title{
A RECEPÇÃO DO CONCEITO DE AUFKLÄRUNG KANTIANO NA DIALÉTICA DO ESCLARECIMENTO
}

\section{THE RECEPTION OF THE KANTIAN CONCEPT OF AUFKLÃRUNG IN THE DIALETIC OF ENLIGHTENMENT}

\author{
Caio Ferrari de Castro Melo ${ }^{1}$ \\ (caioferrari.c@gmail.com)
}

\begin{abstract}
RESUMO
Esse trabalho investiga a questão da recepção do conceito kantiano de Aufklärung por Theodor W. Adorno e Max Horkheimer em sua obra Dialética do Esclarecimento. Tem-se como objeto o conceito de esclarecimento e a problemática a ser desenvolvida se restringe ao modo como foi incorporado o conceito kantiano de esclarecimento por Adorno e Horkheimer, seu sentido e alcance, suas continuidades e descontinuidades em relação ao que foi teorizado por Immanuel Kant. Chegamos à conclusão de que, apesar das semelhanças entre como o conceito é empregado pelos autores, Adorno e Horkheimer mobilizam o conceito de esclarecimento contrapondo-o ao seu desenvolvimento histórico.
\end{abstract}

Palavras-chave: Dialética do Esclarecimento. Aufklärung. Kant. Adorno. Horkheimer.

\begin{abstract}
This paper investigates the reception of the Kantian concept of Aufklärung by Theodor W. Adorno and Max Horkheimer in their work Dialectic of Enlightenment. The objective of this inquiry is the concept of enlightenment and the discussion that it develops is limited to how the Kantian concept of enlightenment was incorporated by Adorno and Horkheimer, its meaning and range and its continuities and discontinuities in relation of what was theorized by Immanuel Kant. We got to the conclusion that, despite the resemblances with the way the concept was used by the authors, Adorno and Horkheimer used the concept of enlightenment to oppose to how its historic development.
\end{abstract}

Palavras-chave: Dialectic of Enlightenment. Aufklärung. Kant. Adorno. Horkheimer.

\section{INTRODUÇÃO - TEMA, OBJETO, PROBLEMÁtiCA DE PESQUISA E MÉTODO}

\footnotetext{
${ }^{1}$ Mestrando em Teoria Geral e Filosofia do Direito pela Universidade de São Paulo (USP). CV Lattes: http://lattes.cnpq.br/4546962053439228.

ORCID: https://orcid.org/0000-0002-7026-8841.
} 
O presente trabalho investiga a questão da recepção do conceito kantiano de Aufklärung, também chamado esclarecimento, por Theodor W. Adorno (1903-1969) e Max Horkheimer (1895-1973) em sua obra Dialética do Esclarecimento (ADORNO E HORKHEIMER, 1985). Tem-se como objeto o conceito de esclarecimento e a problemática a ser desenvolvida se restringe ao modo como foi incorporado o conceito kantiano de esclarecimento por Adorno e Horkheimer, seu sentido e alcance, suas continuidades e descontinuidades em relação ao que foi teorizado por Immanuel Kant (1724-1804).

A teoria crítica, desde que teve seu projeto anunciado no discurso de posse de Horkheimer (1999) no Instituto de Pesquisas Sociais de Frankfurt em 1931, procura se distinguir da chamada teoria tradicional, distinção melhor apresentada no texto Teoria Tradicional e Teoria Crítica, de 1933. A busca por se distinguir da Teoria Tradicional, bem como a proposta de revitalizar o projeto crítico do marxismo através de uma abordagem interdisciplinar, marcaram os diagnósticos de tempo dos pensadores situados nessa corrente de pensamento, de modo que muitas de suas pesquisas apontaram insuficiências, falhas e catástrofes associadas ao modo de produção capitalista e a cultura burguesa.

A incorporação de novos saberes como a psicanálise freudiana, por exemplo, além do diagnóstico de modernidade weberiano ao marxismo foram essenciais a essa crítica multifacetada da sociedade capitalista tardia. Entendemos, contudo, que, a despeito da variedade de objetos estudados por essa corrente como, por exemplo, a indústria cultural, a constituição da subjetividade da classe trabalhadora e a família moderna, em especial no período da chamada primeira geração de teóricos críticos que se inicia na década de 1930, o tema da crítica do projeto político do esclarecimento tal como propagado pela ideologia burguesa é ponto fulcral que merece ser compreendido a fim de que possamos entender como opera o modelo crítico apresentado especificamente por Adorno e Horkheimer.

Para compreender a crítica destes autores ao projeto político do esclarecimento, investigaremos, portanto, o conceito de Aufklärung tal como foi proposto por Immanuel Kant e depois recepcionado por Adorno e Horkheimer.

O principal método a ser empregado na realização desta tarefa é a leitura dos textos Resposta à pergunta: O que é esclarecimento?, de Kant (2011) e Dialética do Esclarecimento, de Adorno e Horkheimer (1985). Assim, pretende-se conseguir expor os movimentos argumentativos dos autores em sua estrutura e, consequentemente, evidenciar o modo como tematizam o conceito. Não nos furtaremos, entretanto, de fazer referência a outros textos, sejam dos próprios autores, como de comentadores, a 
fim de melhor ilustrar argumentos expostos na leitura das duas principais obras acima mencionadas. No caso de Adorno e Horkheimer, serão privilegiados os textos circunscritos ao diagnóstico da década de 1940, como Eclipse da Razão (ADORNO E HORKHEIMER, 2015), tendo em vista a existência de diferenças na argumentação e nas conclusões destes autores ao longo da sua produção intelectual (NOBRE, 2013, p. 44).

\section{O AUFKLÄRUNG DE KANT}

\subsection{Etimologia e história do Aufklärung}

O termo em alemão Aufklärung, hoje traduzido por "esclarecimento", que se fez muito conhecido através do texto de Kant Resposta à pergunta: $O$ que é o esclarecimento?, carrega, assim como todos os conceitos, uma historicidade. Seria, portanto, um anacronismo, empregar sem nenhuma ressalva o sentido que hoje emprestamos a este conceito ao analisarmos uma situação em outra época ou contexto sociocultural. É por isso que também se faz necessária a investigação aqui proposta.

Aufklärung já foi traduzido para o português do Brasil como "iluminismo". Contudo, o significante Aufklärung não só designa o movimento filosófico-científico do iluminismo, mas também uma certa prática e forma de entender a moral que o termo "iluminismo" não tem a capacidade de explicar suficientemente. Para a tradução, o uso do substantivo esclarecimento também é mais acertado por permitir a tradução de verbos como aufklären em "esclarecer" e de substantivos como aufgeklärt em "esclarecido" (ALMEIDA, 1985, p. 8).

Em dezembro de 1784, quando é publicado o reconhecido escrito de Kant a respeito do esclarecimento, o termo já vinha sendo discutido (OLIVEIRA, 2011, p. 10). Sendo assim, não foi Kant que empregou o termo pela primeira vez, mas seu texto tocava a uma discussão corrente à época em que vários outros autores como, por exemplo, Moses Mendelssohn e Friedrich Schiller também debatiam sobre o assunto.

Quem iniciou as discussões sobre o Aufklärung foi o pastor alemão Johann Friedrich Zöllner (1753-1804). Em escrito sobre o casamento civil e a religião formulou a pergunta: $O$ que é esclarecimento?. Na época, surgia a crença absoluta na capacidade e autonomia da razão, a qual se contrapunha a outras crenças calcadas na tradição e na religião. A provocação feita pelo pastor berlinense levou a uma série de tentativas de 
intelectuais da época a tentar responder à pergunta, sendo Immanuel Kant um deles.

\subsection{Conceito de esclarecimento em Kant}

Kant inicia o seu texto de caráter opuscular com uma sentença bem direta a respeito do esclarecimento: "Esclarecimento é a saída do ser humano de sua menoridade, menoridade essa na qual ele se inseriu por sua própria culpa” (KANT, 2011, p. 23). É possível perceber aí alguns elementos que serão explorados mais adiante e já é possível extrair algumas inferências. Para Kant, o esclarecimento é um estágio do ser humano que deixou a menoridade, sendo essa menoridade uma perniciosa condição resultante da responsabilidade do próprio ser humano enquanto "indivíduo".

O autor utiliza o termo Aufklärung ao longo do texto com frequência em oposição às ideias de: "menoridade"; "preguiça"; "covardia"; "falta de resolução"; "falta de coragem"; "comodidade"; "tutorado"; "gado doméstico"; "criatura tranquila"; "passividade" (KANT, 2011, pp. 23-25; 28), entre outras.

Para Kant, a menoridade é a “[...] incapacidade de se servir do seu próprio entendimento sem a condução de outrem" (2011, pp. 23-24). Trata-se da incapacidade de usar de modo autônomo a própria razão individual para pensar e agir. $\mathrm{O}$ autor acrescenta que a pessoa se torna culpada pela própria menoridade não em razão de uma incapacidade natural, mas da falta de confiança ou coragem. Ser esclarecido implica, portanto, uma dimensão moral e não uma capacidade natural para se raciocinar ou agir do modo mais racional. $\mathrm{O}$ valor do esclarecimento não está no saber ou na verdade, mas no fundamento ético de agir conforme a própria convicção. Essa posição se alinha perfeitamente com a proposta da filosofia ética de Kant de um imperativo categórico que podemos observar especificamente na obra Metafísica dos Costumes (2013).

Aquele que não atingiu a maioridade (o esclarecimento, portanto) é, segundo o Kant (2011, p. 24), em consequência de sua incapacidade moral de se valer do próprio entendimento, apequenado intelectualmente por aqueles que se tornam seus tutores. Nessa condição, em que não é preciso fazer esforço, o ser humano tutorado é incentivado a entender a busca pelo esclarecimento como algo "[...] além de penoso, muito perigoso" (2011, p. 24). A atividade de tutoria primeiro enfraquece a razão do tutorado, depois lhe imputa o medo de "[...] arriscar um passo fora do andador" (2011, p. 24), reforçando ainda mais a falta de coragem que o levou a ser tutorado. Assim, a menoridade se transforma 
quase como que uma natureza $(2011$, p. 25) e torna-se muito difícil a um ser humano se desvencilhar dela.

Kant afirma que os "preceitos e as fórmulas" (2011, p. 25) são instrumentos mecânicos de uso racional que se valem do "[...] mau uso dos dons naturais [...]" (KANT, 2011, p. 25). Esses instrumentos são considerados grilhões de uma menoridade perpétua. O autor coloca que, mesmo que essas fórmulas e preceitos fossem deixados de lado, dificilmente se conseguiria superar a menoridade, pois as pessoas não estariam habituadas a pensar livremente.

Isso não significa, no entanto, que não seja possível esclarecer-se por si mesmo. Kant defende a ideia de que um público não tutorado, deixado livre, inevitavelmente tende ao esclarecimento, mesmo que lentamente (2011, p. 26). A ideia de liberdade defendida por Kant é, especificamente, a "[...] liberdade de fazer o uso público de sua razão por toda a parte" (2011, p. 26). O uso público da razão é o uso autônomo da razão que faz alguém com conhecimento no assunto, um erudito, diante de um público letrado. Trata-se da manifestação do seu pensamento autônomo diante de outros, de um público com algum conhecimento. Kant não chega a dizer expressamente, mas, segundo entendemos, a manifestação da razão autônoma do erudito frente aos letrados tem o propósito de ser exposta ao escrutínio do público que pode, por sua vez, pensar a respeito do assunto por si próprio e, assim, expor o uso que faz da sua própria razão ao público de letrados. Dessa forma, segundo Kant, se houver liberdade de uso público da razão, um público tende a conquistar lentamente o esclarecimento que não pode lhe ser dado pronto por ninguém.

O uso privado da razão, em oposição ao uso público da mesma, é aquele que o erudito ou intelectual pode fazer em um cargo específico ou função a ele confiada. Trata-se da pressuposição de uma unanimidade artificial na razão que obriga o erudito a usar da sua razão para as finalidades da função que está exercendo. Kant entende que, no caso do uso privado da razão, não se trata exatamente de raciocinar, mas sim de obedecer (2011, p. 27). Entendemos que a situação é similar àquela descrita anteriormente de aplicar mecanicamente as "fórmulas e os preceitos", atividade que não leva ao esclarecimento.

O uso privado da razão, contudo, pode ser compatibilizado com o esclarecimento. Se o uso privado da razão existir de forma restrita, ele não impede o progresso do esclarecimento (KANT, 2011, p. 27). O autor defende que, em uma sociedade cosmopolita, o erudito pode fazer uso de sua razão diante de um público por meio de escritos e, assim, raciocinar e se esclarecer. Para ele, o fato de um clérigo, por exemplo, ser 
contratado sob a condição do uso privado da razão para professar doutrina religiosa de acordo com o estipulado pela igreja que serve, não impede o mesmo de, enquanto um erudito, dizer o que pensa fazendo uso da sua razão para criticar entidade religiosa de que faz parte (KANT, 2011, pp. 28-29).

Segundo entendemos, é possível notar aqui como a separação entre vida privada e vida pública é algo crucial para que ocorra o esclarecimento nos termos de Kant. Na vida pública, na vida do ser humano em comunidade, seja sob o comando de um empregador, seja em uma função a serviço da coletividade como o Estado, o uso privado da razão se faz necessário para executar tarefas e cumprir objetivos dados. Na vida privada, por outro lado, deve imperar a liberdade para o uso público da razão, do contrário os indivíduos não se esclarecerão. Essa separação rígida entre vida privada e vida pública, sendo que à primeira cabe a liberdade de pensamento, é essencial, portanto, para a concretização do esclarecimento dos seres humanos.

Há em Kant também uma crença de que os esclarecidos e o esclarecimento progridem, no sentido de que os homens ampliam seus conhecimentos, purificam-se de enganos e, assim, se desenvolve o esclarecimento. $\mathrm{O}$ autor entende que não se vive uma época esclarecida, mas sim de esclarecimento. Prognostica que há tendências evidentes que os impedimentos ao esclarecimento universal se tornaram gradativamente menores. Kant acredita que o tempo em que vive é a época do esclarecimento, o século de Frederico II, um déspota esclarecido da Prússia conhecido por defender ideias progressistas de liberdade e tolerância religiosa.

$\mathrm{Na}$ toada desse otimismo com relação ao progresso do esclarecimento, Kant entende que a cada grau de liberdade civil, aumenta a liberdade do espírito do povo (2011, p. 35). Por outro lado, em graus menores de liberdade civil, a liberdade do espírito do povo é menor, mas expande-se mais fortemente a sua capacidade. Isso quer dizer que, ao mesmo tempo em que há menos liberdade civil para um povo, ele tende a desenvolver mais suas capacidades nos assuntos de espírito que lhe são permitidos e, inversamente, com mais liberdade civil, os esforços do povo se tornam dispersos, mas atingem mais áreas do conhecimento humano. A inclinação e a vocação para o livre pensar que Kant entende serem naturais aos seres humanos é apresentada, portanto, como uma semente em que a liberdade é o invólucro que limita o seu desenvolvimento, mas, ao mesmo tempo, o direciona (2011, p. 36).

Temos, assim, que o esclarecimento kantiano se configura como parte de um projeto de desenvolvimento, de progresso, da humanidade em direção a um aperfeiçoamento ético e racional, com pressupostos liberais ou liberalizantes. Bem exposto o modo como Kant entende o esclarecimento, passemos a analisar o modo como Adorno e 
Horkheimer se apropriam desse conceito na Dialética do Esclarecimento para após mostrarmos as confluências e divergências que estes autores têm para com filósofo iluminista.

\section{DIALÉTICA E AUFKLÄURUNG}

\subsection{Notas prévias sobre contexto da produção de Dialética do Esclarecimento}

A obra Dialética do Esclarecimento foi produzida em um momento específico da produção intelectual de Adorno e Horkheimer e da história da teoria crítica, o período do declínio do movimento nazifascista, mais especificamente 1944. É preciso levar isso em consideração se quisermos entender o livro. Afinal, ele possui um objetivo específico: entender porque a humanidade regride em direção à barbárie ao invés de progredir em direção a um estado verdadeiramente humano (ADORNO e HORKHEIMER, 1985, p. 11). Esse objetivo é consonante com uma característica da teoria crítica que é a tentativa de compreender as relações de dominação e as suas possibilidades de superação (NOBRE, 2013, p. 35).

É sugerido como texto para auxiliar o entendimento da obra a Dialética do Esclarecimento (1985), a obra de Max Horkheimer, Eclipse da Razão (2015). Isso porque a última é considerada como um epítome da primeira (HORKHEIMER, 2015, p.9). É possível, portanto, ter apoio no livro de Horkheimer para entender a Dialética. Tal chave de leitura faz ainda mais sentido se tomarmos em consideração o fato de que a produção do livro de Theodor W. Adorno e Max Horkheimer é resultado da datilografia de uma discussão entre os autores pela esposa do primeiro, Gretel Adorno. Não é possível, portanto, dizer quais partes da obra foram escritas por um ou por outro (ADORNO E HORKHEIMER, 1985, p. 9-10).

Também é característico desta obra a organização em dois capítulos intercalados por dois excurso, dois estudos de caso que relacionam filosofia e literatura, além de um capítulo final com notas e esboços. Essa organização característica dá um caráter ensaístico ao livro, o que dificulta a sua sistematização e, possivelmente, indica uma escolha estética que reflete a pretensão de evitar a interpretação sistemática dessa obra que tem como subtítulo "fragmentos filosóficos".

O livro foi escrito na época em que os autores e o Instituto de Pesquisa Social a que estavam ligados se refugiaram nos Estados Unidos (ADORNO E 
HORKHEIMER, 1985, p. 9) e já se vislumbrava a derrota do regime nazifascista na Alemanha pelos Aliados. A Dialética do Esclarecimento se situa no que poderíamos chamar de segundo diagnóstico e modelo crítico, o qual se desenvolve a partir da década de 1940.

Segundo NOBRE (2013, p.44), nos escritos da década de 1940, os autores haviam abandonado a perspectiva da década anterior de que o nazismo era um bloqueio temporário às perspectivas de emancipação. Isso porque, com a derrocada do nazismo, viu-se surgir um capitalismo administrado, que não tem frente a si um Estado indiferente à economia, mas um Estado que planeja e intervém na produção para perpetuá-la, o que causa um bloqueio estrutural da emancipação (NOBRE, 2013, p. 47). Isso significa que há uma primazia da política sobre a economia, uma característica do capitalismo tardio que está presente no diagnóstico da Dialética.

Em certa medida, está submerso na Dialética a tese de que o nazismo não é um acaso, ou que ele possa ser derrotado definitivamente pelas armas. Para os autores, conforme repetiram posteriormente em Eclipse da Razão (2015, p. 7) e Educação após Auschwitz (ADORNO, 1995, p. 121), para que a vitória sobre o nazismo seja definitiva, é preciso desenvolver uma reflexão crítica que possa extirpar os elementos antissemitistas que possibilitam a ocorrência de barbáries como Auschwitz, elementos estes que estão presentes na sociedade capitalista industrial moderna.

A crítica que pretendem fazer Adorno e Horkheimer se dá pelo método de evidenciar a incompatibilidade entre o esclarecimento como realmente é e o seu conceito, exigindo do objeto a realização daquilo que está contido no último (COHN, 1998, p. 6). Segundo Cohn (1998, p. 6), esse procedimento permite expor os limites da realização do conceito de esclarecimento, o qual é apresentado como se estivesse concretizado.

\subsection{Sentido e alcance do conceito de esclarecimento na Dialética do Esclarecimento}

Adorno e Horkheimer possuem uma interpretação bem particular do termo "esclarecimento". O conceito que os autores expõem tem como um de seus sentidos um projeto político cujo o programa é o desencantamento do mundo. A meta desse projeto é extirpar a imaginação e substituí-la pelo saber, consolidando assim a dissolução dos mitos (ADORNO e HORKHEIMER, 1985, p. 17).

O esclarecimento e os esclarecedores pretendem fazê-lo submetendo ao seu intelecto a natureza, aqui tanto no sentido de fenômenos naturais exteriores aos 
homens como também a própria natureza humana (ADORNO e HORKHEIMER, 1985, p. 18). A abstração, o instrumento do esclarecimento por excelência, enforma o objeto e a distância do sujeito (ADORNO e HORKHEIMER, 1985, p. 24), possibilitando assim a universalização de esquemas, fórmulas em uma lógica uniforme, sem contradições dentro do seu sistema lógico (ADORNO e HORKHEIMER, 1985, p. 71). Isso permite a sua reprodução e coloca tanto o enfoque dos objetos, como a percepção dos sujeitos, nos trilhos de um pensamento direcionado. Esse pensamento direcionado visa a autopreservação do "eu" pela submissão da natureza.

Segundo Almeida (1985, pp. 7-8), na Dialética do Esclarecimento (ADORNO e HORKHEIMER, 1985) o termo esclarecimento é “[...] usado para designar o processo de 'desencantamento do mundo', pelo qual as pessoas se libertam do medo de uma natureza desconhecida, à qual atribuem poderes ocultos para explicar seu desamparo em face dela". Por essa razão, o esclarecimento de que falam Adorno e Horkheimer não é o iluminismo, a ilustração, um movimento filosófico de uma época determinada. Segundo o tradutor da obra para o português (ALMEIDA, 1985, pp. 7-8), esclarecimento se refere ao processo histórico de desfazimento dos mitos em que os homens acreditam, o qual corresponde ao processo de racionalização que ocorre na filosofia e na ciência. De fato, os autores não se referem especificamente ao movimento histórico do iluminismo com o termo Aufklärung, tanto que remetem o processo de esclarecimento à mitologia grega, especificamente à Odisseia.

Adorno e Horkheimer expõem duas de suas principais teses a respeito do esclarecimento no primeiro excurso através da análise da Odisseia como momento da história do pensamento da civilização ocidental em que se inicia o processo de esclarecimento. Nesse excurso, os autores defendem duas teses principais: 1) o mito já é esclarecimento e 2) o esclarecimento acaba por reverter à mitologia (ADORNO e HORKHEIMER, 1985, p. 15).

As consequências desse processo de esclarecimento são expostas no segundo excurso. Os autores mostram os efeitos desastrosos da forma como o esclarecimento se desenvolveu. Expõe-se o desenvolvimento do processo de esclarecimento com base em Kant, Sade e Nietzsche. O objetivo é mostrar "[...] como a submissão de tudo aquilo que é natural ao sujeito autocrático culmina exatamente no domínio de uma natureza e uma objetividade cegas" (ADORNO e HORKHEIMER, 1985, p. 15).

Para os autores, o problema não está no esclarecimento em si, mas na forma como ele se desenvolveu. Defende-se que o esclarecimento se autodestruiu (ADORNO e HORKHEIMER, 1985, p. 13) e que, assim, o pensamento pragmático ou técnico 
característico do esclarecimento perde seu "caráter superador" e "também sua relação com a verdade" (ADORNO e HORKHEIMER, 1985, p. 13). O esclarecimento se destruiu porque se recusa a pensar sobre si mesmo. Trata-se de uma expressão do "movimento real da sociedade burguesa" (ADORNO e HORKHEIMER, 1985, p. 13) que se nega a confrontar a consciência racional com a realidade efetiva para chegar à verdade. Fazendo isso, ela nega a sua pretensão de chegar à verdade.

No âmbito da cultura, é possível observar esse embotamento do esclarecimento que é causa e, ao mesmo tempo, consequência, no sistema da indústria cultural, formado principalmente por rádios, revistas e cinema. Esse sistema que se destina à circulação da cultura das massas, ignora a lógica interna de cada produção cultural e a submete completamente à lógica do sistema social, que seria dada pela economia (ADORNO e HORKHEIMER, 1985, p. 100). A indústria cultural teria, portanto, como consequência, a padronização e produção em série de obras de entretenimento as quais teriam o papel de adestrar o espectador de modo a atrofiar a sua imaginação e atividade intelectual (ADORNO e HORKHEIMER, 1985, p. 104).

A atrofia do pensamento dá margem a todo tipo de relativização da busca pelo verdadeiro e, ao mesmo tempo, rotula as tentativas de se percorrer esse caminho como utópicas, anticientíficas e mentirosas. Recai, portanto, o esclarecimento no mito. O esclarecimento, que já é direcionado desde seus pontos de partida pelo princípio da nãocontradição, continuando pelos métodos que são os cientificamente aprovados e até o seu fim último, que é o da autopreservação, não permite o exercício da razão fora desses trilhos. Nesse ponto, resta ao exercício do intelecto apenas a subsunção de fórmulas e preceitos à natureza humana e exterior ao homem, expandindo e aperfeiçoando a sua capacidade de dominar os objetos em prol da autopreservação.

A repetição na aplicação de fórmulas, que é a forma característica de se fazer ciência no esclarecimento, se assemelha aos rituais míticos. Cria-se um "ritual do pensamento" (ADORNO e HORKHEIMER, 1985, p. 33) em que é preciso consumar determinados atos rigorosamente para obter um mesmo resultado. No entanto, essa mística é ainda o pior dos mitos, pois o esclarecimento é rígido e totalitário. Nos rituais, pelo menos há uma singularidade dos objetos envolvidos em determinada prática mágica, mas no esclarecimento não há nenhum conteúdo que não seja substituível, subsumido pelas fórmulas prontas de se enxergar o real. "A substitutividade converte-se em fungibilidade universal" (ADORNO e HORKHEIMER, 1985, p. 22). 
Nesse contexto de repetição, a matemática é a expressão mais evidente desse tipo de uso do intelecto que vê na dominação o seu critério de verdade. O procedimento matemático, quando coloca uma incógnita em uma equação, já predefiniu anteriormente o comportamento do valor, seja ele qual for. É nessa predefinição que está a inverdade do esclarecimento e não na decomposição pela reflexão ou no método analítico (ADORNO e HORKHEIMER, 1985, p. 32).

O exercício da razão instrumental nos moldes em que o esclarecimento se desenvolveu exige também, para o seu sucesso, um sujeito ajustado às operações que deve realizar. Como só há uma "[...] relação entre o sujeito e o objeto, entre o significado racional e o portador ocasional do significado" (ADORNO e HORKHEIMER, 1985, p. 22), o sujeito precisa ser padronizado, papel que a indústria cultural cumpre primorosamente, por exemplo, por meio do filme sonoro que guia a atenção do espectador de modo tão restrito que ele não consegue refletir sobre o que vê (ADORNO e HORKHEIMER, 1985, p. 104).

Eliminada a diferença entre os sujeitos e os objetos, que podem ser facilmente intercambiáveis dentro de um esquema já pré-definido, o processo do pensamento se torna autônomo, automático (ADORNO e HORKHEIMER, 1985, p. 33). Nesse contexto de exercício intelectual não se pensa o pensamento e não faria diferença a substituição de certos sujeitos por outros. A consequência imediata desse processo de mecanização do pensamento é que os sujeitos interiorizam para si a ratificação do mundo como ele é. Eles aprendem a manipular esses instrumentos da razão instrumental e perdem progressivamente a capacidade de pensar criticamente. Há um embotamento da razão crítica do sujeito.

Por fim, a última consequência do processo de esclarecimento na forma como Adorno e Horkheimer identificam que ele ocorreu, é a impossibilidade de se pensar os efeitos negativos do progresso do esclarecimento e o caráter reprodutor do sistema do esclarecimento no qual os sujeitos se inserem. Como o esclarecimento não se volta contra si mesmo, mas apenas se expande e se intensifica, os sujeitos não conseguem pensar nos fins políticos do uso da razão e da ciência. Esses sujeitos alienados se conformam com os efeitos negativos de desumanização que o progresso do esclarecimento promove na sua empreitada de neutralizar as singularidades dos sujeitos na sua relação com os objetos.

A razão esclarecida se torna poderosa, mas, ao mesmo tempo, cega, porque os sujeitos que a operam não conseguem dirigi-la e, assim, ficam obstaculizadas as perspectivas de emancipação, se perpetua a dominação de que os sujeitos não conseguem se livrar. É como sintetizado pelos autores no seguinte trecho: 
O mito converte-se em esclarecimento, e a natureza em mera objetividade. $O$ preço que os homens pagam pelo aumento de seu poder é a alienação daquilo sobre o que exercem o poder. $O$ esclarecimento comporta-se com as coisas como o ditador se comporta com os homens. Este conhece-os na medida em que pode manipulá-los. O homem de ciência conhece as coisas na medida em pode fazê-las. É assim que seu em-si torna para ele. Nessa metamorfose, a essência das coisas revela-se como sempre a mesma, no substrato da dominação. (ADORNO e HORKHEIMER, 1985, p. 21, grifos nossos).

\section{CONSIDERAÇÕES FINAIS - CONTINUIDADES E DESCONTINUIDADES NA RECEPÇÃO DO CONCEITO DE AUFKLÄRUNG}

O método da crítica que Adorno e Horkheimer exercitam na Dialética, como podemos ver, leva o conceito de esclarecimento kantiano às suas últimas consequências. O confrontam com a situação atual do esclarecimento para revelar as insuficiências desse projeto filosófico que tem implicações políticas, morais e científicas.

Ao contrário de Kant, que tinha uma visão otimista em relação ao progresso do esclarecimento, Adorno e Horkheimer possuem uma perspectiva bem mais pessimista das consequências do desenvolvimento do esclarecimento. Enquanto Kant achava que o esclarecimento fosse progredir constante e unidirecionalmente, Adorno e Horkheimer identificam que o esclarecimento reverteu ao mito, já que apenas uma face da razão se desenvolveu em detrimento da outra. Ao invés de progredir em uma direção, o esclarecimento experimenta um voo sem piloto: "A máquina ejetou o piloto, ela corre cegamente pelo espaço" (HORKHEIMER, 2015, p. 141).

Kant era um liberal e, para ele, as massas esclareceriam por si próprias, desde que não tuteladas. A liberdade de pensamento e expressão daria a medida e a extensão do esclarecimento apenas. Ora, Adorno e Horkheimer, para além de uma visão de liberdade formal, estão levando em consideração que a sociedade de sua época possui barreiras materiais e ideológicas que não permitem o esclarecimento dos indivíduos, muito pelo contrário, enformam os sujeitos e atrofiam a sua capacidade de pensar. Segundo Kant (2011, p. 24), o tutor se arvora sobre o tutelado em razão da preguiça e da covardia deste último. $O$ tutor embota o pensamento e assusta o tutelado, reforçando o seu afastamento do esclarecimento. Assim opera a indústria cultural, oferecendo e, simultaneamente, 
adestrando os consumidores para o fácil, para um entretenimento baseado em modelos e fórmulas prontas.

Kant identifica a razão instrumental como um grilhão ao esclarecimento de uma pessoa (2011, p. 25). Adorno e Horkheimer estão de acordo com isso. Conforme já exposto anteriormente, é possível ver como Adorno e Horkheimer e Kant repudiam o uso de fórmulas e preceitos prontos. Se afastam, entretanto, os teóricos críticos do filósofo iluminista na sua interpretação a respeito de como estão relacionados esclarecimento e as fórmulas prontas. Kant, de sua posição, acredita que o esclarecimento está se desenvolvendo no sentido de não depender das chamadas fórmulas prontas. Adorno e Horkheimer, por outro lado, veem na forma como o esclarecimento se desenvolveu uma associação forte entre o uso desses artifícios e o esclarecimento.

Kant coloca que o uso privado da razão não é uma ameaça ao uso público da razão, desde que exista a liberdade para fazer o uso público. Ele admite a necessidade e a coexistência de um tipo de uso da razão com outro. Em Adorno e Horkheimer, o mesmo fenômeno, o da possibilidade de harmonia entre dois usos diferentes da razão, privado e público, é tematizado como razão subjetivista e razão objetivista. Não há, para os frankfurtianos, uma ojeriza à razão subjetivista, ou instrumental, em si, mas na forma que ela se desenvolveu, a forma de uma hegemonia de uma maneira de pensar sobre outra.

A ideia defendida por Kant de progresso é algo que está em desacordo com o que pensam Adorno e Horkheimer. Enquanto o primeiro tem uma visão de progresso baseada na ampliação do conhecimento e na purificação de enganos (KANT, 2011, p. 30), Adorno e Horkheimer defendem que esse é um progresso meramente técnico, que não leva ao progresso da humanidade. O que Adorno e Horkheimer notam, e Kant desconsidera, é que pode ser feito o uso da razão sobre outros sujeitos com o objetivo de adestramento para o consumo, levando ao embotamento do pensamento e a consequente realização do esclarecimento em mito. Podemos perceber aqui uma semelhança com algumas das teses de Walter Benjamin sobre o conceito de história, em especial a tese IX (LÖWY, 2005, p. 87) e a tese XIII. Nessa última, Benjamin defende expressamente:

A representação de um progresso do gênero humano na história é inseparável da representação do avanço dessa história percorrendo um tempo homogêneo e vazio. A crítica à representação desse avanço tem de ser a base da crítica da representação do progresso em geral. (LÖWY, 2005, p. 116). 
Interessa notar que os fenômenos sociais descritos por Adorno e Horkheimer na Dialética do Esclarecimento (1986) se conectam à tese de Benjamin pelo fato de que os primeiros explicam o fenômeno social que impede a crítica da representação do avanço histórico e, portanto, da própria crítica da representação do progresso em geral. O que o embotamento do esclarecimento manifestado na indústria cultural faz é, portanto, a constituição do bloqueio à crítica.

No tocante à relação entre saber e liberdade, se nos apropriarmos da metáfora da semente de Kant e a associarmos ao diagnóstico de Adorno e Horkheimer exposto na Dialética, é interessante notar como a restrição da liberdade na forma da negação da razão objetiva cumpriria o fim de maximizar a alocação dos esforços humanos no desenvolvimento da razão subjetivista e, consequentemente, no desenvolvimento das forças produtivas.

À guisa de conclusão, é possível dizer que a raiz da discordância, e, portanto, das diferenças com que vão se contrapor Adorno e Horkheimer em relação a Kant e o seu ideal de esclarecimento, esteja no fato de que Kant não considera os usos políticos da técnica e da ciência que estão ligados ao processo de esclarecimento. Kant, como um homem do seu tempo, tinha um excessivo otimismo em relação às luzes. Ele parece confundir, se adotarmos o ponto de vista de Adorno e Horkheimer, dominação com conhecimento, capacidade de conhecer para agir no mundo por si com o próprio progresso do esclarecimento, apesar de não ser um defensor da razão instrumental.

Isso é demasiadamente perigoso para o pensamento crítico e o verdadeiro progresso da humanidade. Como já demonstramos acima, o processo de esclarecimento que tem em si uma pretensão de neutralidade, que está atrelado de antemão em suas finalidades, leva ao ofuscamento pelo esclarecimento nos termos em que se desenvolveu. Tenta-se tanto confrontar a luz do sol com o olhar mundano que a claridade causa uma cegueira branca.

Entendemos, por fim, que, a despeito da existência de críticas de Adorno e Horkheimer ao esclarecimento burguês e kantiano na forma como ele se desenvolveu, no que tange às limitações e, portanto, parcialidade das investigações aqui apresentadas, os teóricos críticos mencionados possuem diversos pontos de contato com o projeto político do esclarecimento. Contudo, somente na medida em que recuperam o conceito de Aufklärung para contrapô-lo à forma com que se desenvolveu. 


\section{REFERÊNCIAS}

ADORNO, Theodor; HORKHEIMER, Max. Dialética do esclarecimento. Rio de Janeiro: Jorge Zahar, 1985, pp. 99-138.

. "Educação após Auschwitz”. In: Educação e emancipação. São Paulo: Paz e Terra, 1995, pp. 119-138.

ALMEIDA, Guido Antonio de. Nota preliminar do tradutor. In: ADORNO, Theodor; HORKHEIMER, Max. Dialética do esclarecimento. Rio de Janeiro: Jorge Zahar, 1985, pp. 78.

COHN, Gabriel. Esclarecimento e ofuscamento: Adorno e Horkheimer hoje. Revista Lua Nova, n. 43, São Paulo, Cedec, pp. 5-24, 1998.

HORKHEIMER, Max. A Presente Situação da Filosofia Social e as Tarefas de um Instituto de Pesquisas Sociais. Revista Praga, n. 7, São Paulo, Hucitec, p. 121-132, 1999. . Eclipse da razão. São Paulo: Editora Unesp, 2015. . Teoria Tradicional e Teoria Crítica. In HORKHEIMER, Max e ADORNO, Theodor. Textos Escolhidos. São Paulo: Abril Cultural, 1983, pp. 31-68.

NOBRE, Marcos (ORG.). Curso livre de Teoria Crítica. Campinas: Papirus, 2013.

KANT, Immanuel. Metafísica dos Costumes. Petrópolis: Vozes, 2013. et al. O que é Esclarecimento?. Tradução de Paul Cesar Gil Ferreira. Rio de Janeiro: Via Verita, 2011.

LÖWY, Michael. Walter Benjamin: aviso de incêndio: uma leitura das teses "Sobre o conceito de história”. São Paulo: Boitempo, 2005.

OLIVEIRA, Bernardo Barros Coelho de. Introdução. In: KANT, Immanuel et al. $O$ que é Esclarecimento?. Tradução de Paul Cesar Gil Ferreira. Rio de Janeiro: Via Verita, 2011, pp. 9-13. 